\title{
Big data governance, dynamic capability and decision-making effectiveness: Fuzzy sets approach
}

\author{
Majdi Al Saaideh Abbady ${ }^{a^{*}}$, Murat Akkaya ${ }^{a}$ and Arif Sari ${ }^{a}$
}

${ }^{a}$ Girne American University, Cyprus

\begin{tabular}{l}
\hline C H R O N I C L E \\
\hline Article history: \\
Received April 19, 2019 \\
Received in revised format: \\
May 20, 2019 \\
Accepted May 20, 2019 \\
Available online \\
May 20, 2019 \\
\hline Keywords: \\
Fuzzy set \\
Big data \\
Dynamic capability \\
Decision-making, Jordan \\
\hline
\end{tabular}

\begin{abstract}
A B S T R A C T
This article examines the nexus between Big data governance, dynamic capability and decisionmaking. Survey data was garnered from firms in Jordan and fuzzy sets (fsQCA) approach was applied. Fuzzy set configural modeling revealed two causal models for high decision-making effectiveness conditions. First, Big data governance, number of employees and firm age are necessary for higher levels of effective decision-making. Second, dynamic capability, number of employees and firm age are necessary for higher levels of effective decision-making. Insights for practitioners in an emerging economy and possible areas of future research are highlighted.
\end{abstract}

(C) 2018 by the authors; licensee Growing Science, Canada.

\section{Introduction}

With the rapid change in business operation and environment, it is necessity for firms to stay relevant about what they need to anticipate and react to the changes proactively. Several studies discovered that firms cannot realize effectiveness and high-performance if they lack the capabilities required to cope with both external and internal changes (e.g., Fainshmidt et al., 2016; Mikalef \& Krogstie, 2018; Teece, 2007; De Haes \& Van Grembergen, 2015). Dynamic capabilities are defined by Zollo and Winter (2002, p. 340) as an array of a number of collective activities that are both stable and learned by which an organization systematically modifies and/or generates its operational routines in a quest to improve effectiveness. Helfat et al. (2009, p. 4) described dynamic capabilities as an organization's capacity to modify, extend or create its operational competencies purposefully.

According to (Teece, 2007), dynamic capabilities “is a firm's complex and tough-to-replicate capabilities of sensing, seizing and reconfiguration necessary for adapting to changing technological opportunities and customer need". Researchers such as Karna et al. (2016) claim that dynamic capabilities ought to line up with technologies used, and other organizational factors to achieve success in any organization. In addition, while dynamic capability is essential for successful survival in a dynamic business environment (Pezeshkan et al., 2016; Teece, 2007). Weber et al. (2009) opines that, for a firm to achieve its agility objectives and for it to meet the requirement of changing business environment, high-quality data is a prerequisite for such firm. Hundred (100) Petabytes (PB) of data

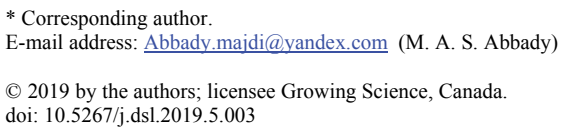


are processed by Google and Facebook, and Terabyte (TB) by Alibaba and its subsidiaries (Chen et al., 2014).

This argument brings Big data into the picture, it denotes huge datasets. It comes with fresh opportunities for the discovery of new values, supports us in gaining a better understanding of values that have been hidden, as well as invites new challenges, such as the effective managing and organizing of such enormous datasets (Abubakar et al., 2017; Chen et al., 2014). Mikalef and Krogstie (2018) argued that big data usage by contemporary firms is a strategic tool that yields superior business value. According to Weber et al. (2009), Big data governance comprises of different activities involving decision-making for data quality management; and the allocation of responsibilities (structural practices), the decision-making process (procedural practices), as the relational responsibilities and links between departments (relational practices).

Shamim et al. (2018) proposed that the management of big data is the major antecedent in decisionmaking and it is also essential to the quality of decision. Because managers and analysts are provided with a powerful set of tools for data visualization, data mining and data analysis (Davenport \& Harris, 2017). Only very little empirical research has been carried out in this area (Mikalef \& Krogstie, 2018). To date, several emphases have been on dynamic capability, with little attention to big data governance and on how both variables affect decision-making effectiveness of firms. To this end, this paper aims to grasps how effective decision making in a firm can be influenced by big data governance and dynamics capability.

\section{Hypotheses development}

Big data as large data volume that is beyond the current on-line technological capacity to process, manage and store efficiently. Big data is high-velocity, high-variety and high-volume information that require state-of-the-art and cost-effective forms of information processing for improved decisionmaking and insight (Gandomi \& Haider, 2015). Lee (2017) suggests that value, volume, velocity, veracity and variety are big data dimensions. According to Mikalef and Krogstie (2018), an increasing number of firms are investing heavily in big data, with the sole aim of gaining a competitive edge over other firms. It was also added that many researchers and practitioners have associated the next big frontier for productivity, competitiveness, and innovativeness to big data. Günther et al. (2017) in their research opined that firms that are dependent on big data to guide their daily operation and organizational strategies are estimated to perform financially better than other firms that do not. This is because, decision making is enhanced, and strategizing is more informed through big data utilization (Günther et al., 2017). Similarly, the capacity a firm possesses to incorporate, develop and reconstruct its external and internal competences when dealing with swiftly changing environments. This allows them gain competitive advantage

\subsection{Dynamic capability and effective decision-making}

Effective decision making requires constant scanning, searching, and exploring markets intelligence and technology. Existing literature suggest that the capacity of organizations in managing information has an impact their performance, process management and customers service delivery through effectiveness of decisions made based on information available to it (Mithas et al., 2011). Wamba et al. (2017) argued that it is a game changer that facilitates effectiveness due to its great strategic and operational potential in the decision-making process. Thus, dynamic capabilities can help organizations identify threats and opportunities (Wilhelm et al., 2015), which allow firms to implement the right responses to their environment and thus improving the relevance of their decisions. The dynamic capability of sensing opportunities and threats includes collecting and filtering competitive market and technological information for decision-making. Sensing is essential, but it is insufficient for effective decision making. Once a quality diagnosis is made as a result of sensing, the dynamic capability of 
seizing comes in to facilitates the implementation of organizational change and strategic action plans (Torres et al., 2018). The third component transforming, entails executing organizational decisions via the revamping of organizational routines, the realigning of assets and the restructuring of the business model (Teece, 2007). Thus, dynamic capabilities influence the effective decision making not just in the aspect of making correct decisions in response to the prevailing circumstances in the business environment but also in ensuring promptness in implementation.

$\boldsymbol{H}_{1}$ : Dynamic capabilities have significant impacts on decision-making effectiveness.

\subsection{Big data governance and effective decision-making}

Research has shown that big data governance is likely to result in performance. Big data governance has ushered significant changes in modern establishments particularly in the procedures of decisionmaking (Janssen et al., 2017). Through enhancement of managerial decisions quality and future forecasting (Kung et al., 2015). Firms that employ data and business analytics are more likely to be productive, make right decisions and boost their revenues in comparisons to competitors that don't (Brynjolfsson et al., 2011). Big data analytics have the potential to extensively minimize risks and improve decision making (Manyika et al., 2011). At best the decisions are made based on experience and the intuition of decision makers. Using big data, managers are enabled to decide based on evidence instead of intuition and this has the perspective to entirely reform management (McAfee \& Brynjolfsson, 2012). Decision making will never remain the same as certain organizations are already making decisions that are effective by analyzing complete datasets from staffs, customers or even sensors implanted in products (Manyika et al., 2011). Based on the extant discussion the following hypothesis is proposed:

$\boldsymbol{H}_{2}$ : Big data governance has a significant impact on decision-making effectiveness.

\subsection{Demographic variables effects}

Research denote that smaller firms are not likely to profit as much due to the scale and scope economies in applying dynamic capabilities (Arend, 2014). The role organizational size plays have been studied as a contingency factor in several types of research in Information System (IS) activities such as data governance and analytics (Raymond \& Bergeron, 2008). Thus, larger firms the more likely will the managers establish formal structures and processes to ensure IS activities including data analytics. On the other hand, it has been reported that smaller organizations are more likely to be well aligned in data analytics and its application due to the greater degree of communication that exists between people in the smaller organizations but in larger organizations, realizing such alignment appears to be a laborious undertaking (Chan et al., 2006). Mikalef et al. (2015) reported smaller firm size increases the chances of business benefiting from IS activities in strategic purchase decision making. Chan and Reich (2007) argued that data analytics are best applied if firm size is small. Contrariwise, bigger firms have the financial capability to invest and govern big data better that smaller firms (Chan et al., 2006). Additionally, enormous amounts of data makes it difficult for younger and inexperience firms to leverage the benefits of dynamic capability and Big data (Carayannopoulos, 2009). Subsequently, there was a report, which indicates that employees in smaller firms are more motivate than those in bigger and older firms (Arend, 2014). The ambiguity in the findings of previous studies made use to propose the following hypotheses;

$\boldsymbol{H}_{3}$ : Dynamic capability interacts with firm type (based on employee number) and firms age to predict higher levels of decision-making effectiveness.

$\boldsymbol{H}_{4}$ : Big data governance interacts with firm type (based on employee number) and firms age to predict higher levels of decision-making effectiveness. 


\section{Materials and methods}

\subsection{Research Instruments}

Dynamic capability - operationalized as a triad second-order construct namely: sensing, seizing and transforming with (3-items) each (Teece 2007; Jantunen et al., 2018) work. Sample of item include "We frequently scan the environment to identify new business opportunities". Big Data governance operationalized as a triad second-order construct namely: structural, procedural and relational practices (Mikalef \& Krogstie, 2018). Structural (2-items), relational (2-items) and procedural (5-items) practices Sample of item include "in our organization, we have controlled practices regarding data management in terms of establishing/monitoring access (e.g., user access) to data". Decision-making effectiveness -operationalized with 3-items (Wang \& Byrd, 2017). Sample of item includes "The speed at which we analyze decisions has increased with the use of business analytics systems and strategies". The response options were anchored on the five-point Likert scale where $1=$ "strongly disagree" and $5=$ "strongly agree".

\subsection{Sampling technique and procedure}

The scale items were adapted from prior works. The items were back-translated by linguistic experts from English to Arabic and vice versa as applicable in prior studies (i.e., Abubakar et al., 2018); followed by a pre-test to evaluate the appropriateness and the presence of ambiguity in wordings and sentence structure. As a next step, we assured the participants of anonymity and confidentiality to reduce common method bias (Podsakoff et al., 2012). The participants are top managers working in several industries (i.e., manufacturing, service, IT \& telecommunication, hotel and hospitality and oil, gas and mining) in Jordan. This study deployed simple random sampling (SRS) technique because of its unbiasedness and aptness to tranquillize classification error (Jahmani et al., 2018). Moreover, with this sampling techniques firms in the whole population have equal chance of being selected, more specifically, any firm can be sampled without bias.

\subsection{Fuzzy sets ( $\left.f_{S} Q C A\right)$}

Complexity theory posits the total net effects of a predictor variable on a response variable is hardly precise nor error-free. This largely because "prediction of behavioral outcomes is a complex process, a set of complex interactions between antecedents (i.e. conjunctural causation) must be considered as a causal model capable of predicting the conditions leading to a desired outcome". Fuzzy set (fsQCA) uses a distinct configuration of causal antecedents to predict response variable. In linear modeling predictors $\mathrm{X}_{1}, \mathrm{X}_{2}$ and $\mathrm{X}_{3}$ are expected to predict $\mathrm{Y}$, whereas, in fsQCA the predictor variables are combines either $\mathrm{X}_{1}$ and $\mathrm{X}_{2}$, or $\mathrm{X}_{1}$ and $\mathrm{X}_{3}$, or $\mathrm{X}_{2}$ and $\mathrm{X}_{3}$ to predict $\mathrm{Y}$ (Olya \& Gavilyan, 2016; Ragin, 1987).

\section{Data analysis and results}

\subsection{Demographic information}

A breakdown of the demographic data are presented in Fig. 1 and the descriptive statistics are presented in Table 1. 


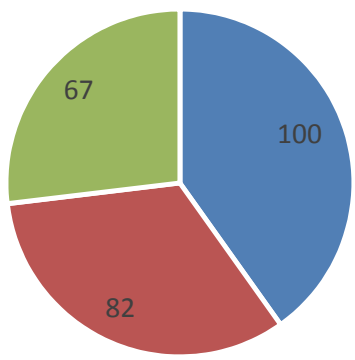

- 50> - -50--100 - $100<$

Number of employees

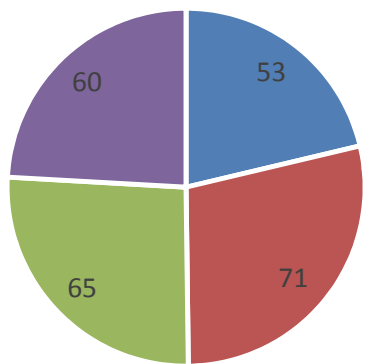

- $1>-1-5=6--10=10<$

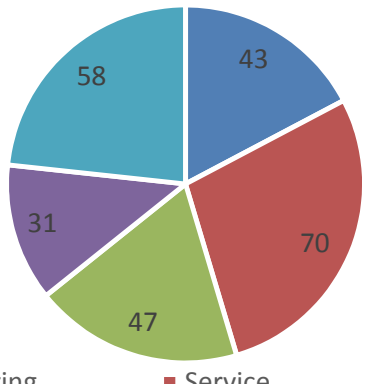

- Manufacturing

- Service

= IT \& Telecommunication - Hotel and Hospitality

- Oil, Gas and Mining Industry

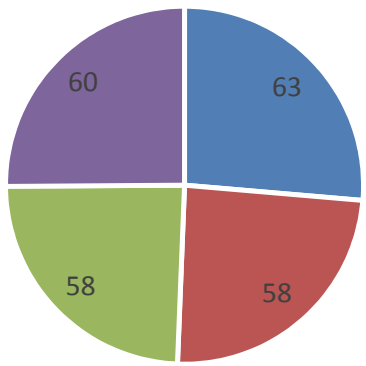

- Research \& development - Marketing \& sales

- Operations

- Human Resources

Firm age

Department

Fig. 1. Personal characteristics of the participants

The proposed configurational model was tested using fsQCA software (Ragin, 2008; Woodside, 2013). This study uses a five-point scale, which makes the scale more suitable to calibrate it into Fuzzy set membership. Following Ragin's (2008) recommendations the calibration process was carried out, where 1.00 (full membership), 0.5 (crossover point) and 0 (full non-membership). In this study the calibration process below was used to convert the scale into Continuous Fuzzy sets.

Calibrate $(x, n 1, n 2, n 3)$

where

$x$ depicts the variable to be transform, $n 1$ is the full membership range set to $4, n 2$ is the crossover point set to 3 and $n 3$ is the full non-membership set to 2

Computational formula is given:

compute: cBigDataGovernance $=$ calibrate (BigDataGovernance, 4,3,2) 
compute: cDynamicCapability = calibrate (DynamicCapability, 4,3,2)

compute: cDecisionMaking = calibrate (DecisionMaking, 4,3,2)

compute: cNoofemp = calibrate (Noofemp, 2.5,2,1.5)

compute: cFirmage $=$ calibrate (Firmage, 3,2.5,2)

\section{Table 1}

Descriptive statistics of the survey items

\begin{tabular}{|c|c|c|}
\hline Variables & Mean (SD) & $\lambda$ \\
\hline \multicolumn{3}{|l|}{ Dynamic Capabilities - Sensing } \\
\hline "We frequently scan the environment to identify new business opportunities" & $2.85(1.37)$ & 1.89 \\
\hline $\begin{array}{l}\text { "We often review our product development efforts to ensure they are in line with what the } \\
\text { customers want" }\end{array}$ & $2.85(1.38)$ & 1.91 \\
\hline $\begin{array}{l}\text { "We use established processes to identify target market segments, changing customer needs and } \\
\text { customer innovation" }\end{array}$ & $2.89(1.38)$ & 1.90 \\
\hline \multicolumn{3}{|l|}{ Dynamic Capabilities - Seizing } \\
\hline $\begin{array}{l}\text { "When opportunities or threats are sensed, our organization has effective routines for drafting } \\
\text { various potential solutions" }\end{array}$ & $2.84(1.39)$ & 1.93 \\
\hline $\begin{array}{l}\text { "When opportunities or threats are sensed, our organization has effective routines for } \\
\text { evaluating and selecting potential solutions" }\end{array}$ & $2.68(1.32)$ & 1.75 \\
\hline $\begin{array}{l}\text { "When opportunities or threats are sensed, our organization has effective routines for } \\
\text { starting on a detailed plan to carry out a potential solution" }\end{array}$ & $2.83(1.40)$ & 1.96 \\
\hline \multicolumn{3}{|l|}{ Dynamic Capabilities - Transforming } \\
\hline $\begin{array}{l}\text { "Our organization can successfully create new or substantially changed ways of } \\
\text { achieving our targets and objectives" }\end{array}$ & 2.97(1.39) & 1.94 \\
\hline $\begin{array}{l}\text { "Our organization can successfully adjust our business processes in response to shifts } \\
\text { in our business priorities" }\end{array}$ & 2.93(1.41) & 1.99 \\
\hline $\begin{array}{l}\text { "Our organization can successfully reconfigure our business processes in order to } \\
\text { come up with new productive assets }\end{array}$ & $2.90(1.44)$ & 2.07 \\
\hline \multicolumn{3}{|l|}{ Big Data Governance - Structural Practices } \\
\hline $\begin{array}{l}\text { "In our organization, we have identified key IT and non-IT decision makers to have the } \\
\text { responsibility regarding data ownership, value analysis and management" }\end{array}$ & $2.73(1.40)$ & 1.96 \\
\hline $\begin{array}{l}\text { "In our organization, we use steering committees to oversee and assess data values and costs" } \\
\text { Big Data Governance - Procedural Practices }\end{array}$ & $3.01(1.52)$ & 2.30 \\
\hline \multicolumn{3}{|l|}{ In our organization, we have controlled practices regarding data management in terms of } \\
\hline "setting retention policies (e.g. Time to live) of data" & $2.82(1.30)$ & 1.70 \\
\hline "backup routines" & $3.09(1.52)$ & 2.31 \\
\hline "establishing/monitoring access (e.g. User access) to data" & $2.97(1.38)$ & 1.91 \\
\hline "monitoring costs versus value of data" & $2.89(1.46)$ & 1.91 \\
\hline \multicolumn{3}{|l|}{ Big Data Governance - Relational Practices } \\
\hline $\begin{array}{l}\text { "In our organization, we educate users and non-IT managers regarding storage utilization and } \\
\text { costs" }\end{array}$ & $3.02(1.43)$ & 2.03 \\
\hline “In our organization, develop communications regarding policy effectiveness and user" & $2.87(1.34)$ & 1.80 \\
\hline \multicolumn{3}{|l|}{ Decision-Making Effectiveness } \\
\hline $\begin{array}{l}\text { "The quality of decisions has improved with the use of business analytics systems and } \\
\text { strategies" }\end{array}$ & $3.03(1.42)$ & 2.00 \\
\hline $\begin{array}{l}\text { "The speed at which we analyze decisions has increased with the use of business analytics } \\
\text { systems and strategies" }\end{array}$ & $3.16(1.42)$ & 2.02 \\
\hline $\begin{array}{l}\text { "We have an increased understanding of our customers/clients/suppliers and competitors with } \\
\text { the use of business analytics systems and strategies" }\end{array}$ & $2.58(1.37)$ & 1.89 \\
\hline
\end{tabular}

Secondly, the researchers generate a truth table using the antecedents under investigation to predict greater level of decision-making effectiveness. Then, the counterfactual analysis for selecting consistent and sufficient causal conditions were obtained (Ragin \& Fiss, 2008). More specifically: Consistency assesses the degree to which a subset relation has been approximated, being analogous to a correlation [and] coverage assesses the empirical relevance of a consistent subset, analogous to a coefficient of determination (Hervas-Oliver et al., 2015, p. 2656). 
The equations below illustrate how coverage and consistency can be calculated. Where $X_{\mathrm{i}}$ represents case i's membership score in set $\mathrm{X}$ and $Y_{\mathrm{i}}$ denotes Case i's membership score in the outcome condition in set $Y$ (Ragin, 2008). The Venn diagram illustrated in Fig. 1 represents the proposed configurational model. This study incorporates two demographic information as the ingredients of a causal configuration for predicting the decision-making effectiveness.

\section{Coverage:}

$$
\begin{aligned}
\left(X_{i} \leq Y_{i}\right)= & \sum\left\{\min \left(X_{i}, Y_{i}\right)\right\} / \sum\left(Y_{i}\right) \\
& \text { Consistency: } \\
\left(X_{i} \leq Y_{i}\right)= & \sum\left\{\min \left(X_{i}, Y_{i}\right)\right\} / \sum\left(X_{i}\right)
\end{aligned}
$$

\section{Consistency:}

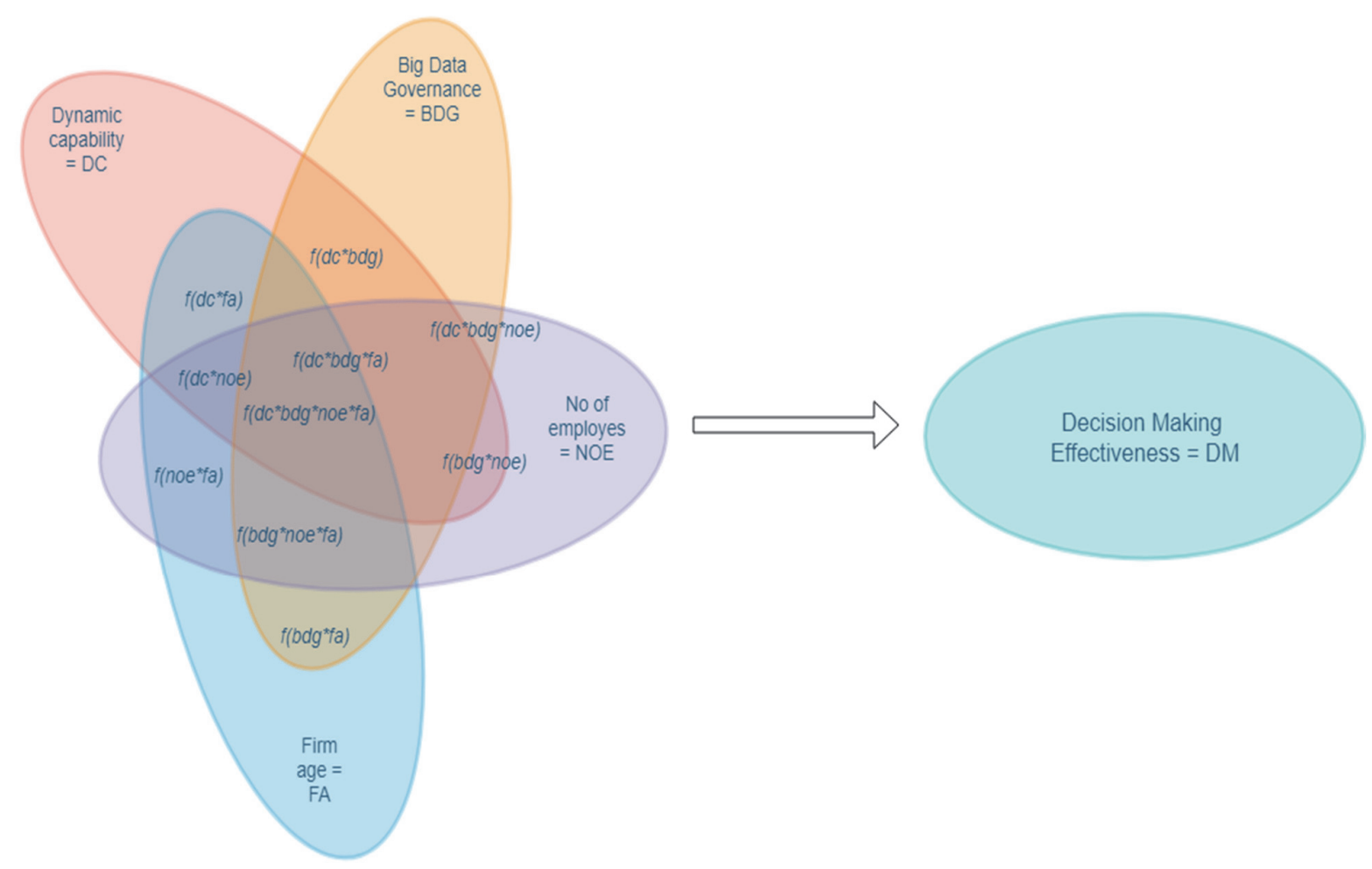

Fig. 2. fsQCA configurational model

The configurational model is illustrated in Fig. 2. The researchers tested for a configurational model that predicts high and low scores for decision-making effectiveness using Quine-McCluskey algorithm. In Table 3, fsQCA generated two causal recipes (solutions) for high scores in decision-making effectiveness (coverage: $\mathbf{0 . 2 4 6}$, consistency: $\mathbf{0 . 7 5 4}$ ).

Solution 1 denotes that high level of big data governance; large number of employees and young firms describes those conditions that are sufficient for decision-making effectiveness. This solution points out that younger firms who utilize big data governance and possess adequate number of employees are more likely to be effective in business decision making.

Solution 2 denotes that high level of dynamic capability; large number of employees and young firm describes those conditions that are sufficient for decision-making effectiveness. This solution points out that younger firms with possession of dynamic capability and adequate number of employees are more likely to be effective in business decision making. 
Table 2

Causal models for predicting decision-making effectiveness

\begin{tabular}{|c|c|c|c|}
\hline Solutions & $\begin{array}{l}\text { Raw } \\
\text { Coverage }\end{array}$ & $\begin{array}{l}\text { Unique } \\
\text { Coverage }\end{array}$ & Consistency \\
\hline \multicolumn{4}{|c|}{ High scores in decision-making effectiveness } \\
\hline \multicolumn{4}{|c|}{ Decision-making effectiveness $=f(b d g, d c$, noe, $f a)$} \\
\hline Solution 1: $f(b d g *$ noe $* \sim f a)$ & .215 & .035 & .764 \\
\hline Solution 2: $f(d c *$ noe * $f a)$ & .211 & .030 & .785 \\
\hline \multicolumn{4}{|l|}{ Solution coverage: .246} \\
\hline \multicolumn{4}{|c|}{ Solution consistency: .754 } \\
\hline \multicolumn{4}{|c|}{ Negation (low) scores in decision-making effectiveness } \\
\hline Solution 1: $f(\sim b d g * f a)$ & .410 & .058 & .771 \\
\hline Solution 2: $f(d c * f a)$ & .318 & .022 & .774 \\
\hline Solution 3: $f($ noe *fa) & .294 & .024 & 672 \\
\hline Solution 4: $f(\sim b d g * d c * \sim f a)$ & .351 & .096 & .815 \\
\hline Solution 5: $f(\sim b d g * \sim d c *$ noe $)$ & .375 & .084 & .818 \\
\hline \multicolumn{4}{|l|}{ Solution coverage: .712} \\
\hline Solution consistency: .701 & & & \\
\hline
\end{tabular}

In Table 2, fsQCA generated five causal recipes (solutions) for low scores (negation) in decisionmaking effectiveness (coverage: 0.712 , consistency: $\mathbf{0 . 7 0 1}$ ).

Solution 1 denotes low level of big data governance practices and the older the firm, describes those conditions that are sufficient for lesser decision-making effectiveness. This solution points out that older firms who do not utilize big data governance practices are less likely to be effective in business decision-making.

Solution 2 denotes that high dynamic capability and the older the firm, describes those conditions that are sufficient for lesser decision-making effectiveness. This solution points out that older firms who possess high dynamic capability are less likely to be effective in business decision-making.

Solution 3 denotes that large number of employees and the older the firm, describes those conditions that are sufficient for lesser decision-making effectiveness. This solution points out that older firms with large number of employees are less likely to be effective in business decision-making.

Solution 4 denotes that low level of big data governance practices, high level of dynamic capability and the younger the firm, describes those conditions that are sufficient for lesser decision-making effectiveness. This solution points out that young firms with high dynamic capability and absence of big data governance practices are less likely to be effective in business decision-making.

Solution 5 denotes that low level of big data governance practices, low level of dynamic capability and large number of employees, describes those conditions that are sufficient for lesser decision-making effectiveness. This solution points out that firms who do not have big data governance practices and dynamic capability but have large number of employees are less likely to be effective in business decision-making. In sum, the present findings further reinforce the above finings, thus, hypotheses 1,2,3 and 4 received support. 


\section{Discussion}

This study builds on existing literature on the concept of big data governance and dynamic capabilities and seeks to understand how they influence effective decision making. The study further enriches these relationships with firm age and number of employee's recipes. First, the present study has revealed that higher levels of dynamic capabilities (and its elements) are necessary and sufficient for effectiveness of decision-making. This is in agreement with Arend (2014) who claims that dynamic capabilities can improve firm performance through informed decision making. This implies that dynamic capabilities heighten the effectiveness of decisions, decision timeliness and relevance (Zollo \& Winter, 2002). Second, the present study has revealed that higher levels big data governance (and its elements) are necessary and sufficient for effectiveness of decision-making. This implies that data management can provide business value through informed decision. This is in agreement with Cole (2017) who stated that big data governance results in greater levels of visibility, which in turn enable managers to take timely action. More specifically, governed and analyzed data unpack hidden business information which guarantees decision effectiveness. Third, firm type (based on employee number) and firm age interact with dynamic capability and Big data governance to predict greater decision-making effectiveness. It appears that high level of Big data governance, large number of employees and younger firms are more likely to make informed-decisions. This further reinforces Chan and Reich (2007) who claim that under certain situations IS activities such as big data governance really improved with firm size. The possible reason for this could the formal structures and processes that bigger firms have which facilitates IS activities which are not typically found in smaller firms. Fourth, it also appears that high level of dynamic capability, large number of employees and younger firms are also more likely to make informed-decisions. This is related to the report of Zollo and Winter (2002) who states that the scope and scale economies of a firm's dynamic capabilities are more evident when it's applied to innovation and decision making. This study corroborates the theoretical and practical assertion that as a firm gets older, the more it struggles to relinquish traditional practices that are not necessarily needed to remain a dynamic business that is capable of reconfiguring procedures and processes. In turn, these older firms appear to be "left out" of particular kinds of knowledge, as a result more unlikely to leverage dynamic capability and big data to manage business threats and opportunities. These restricts the contribution of dynamic capability and big data to the decision making the process of older firms.

\subsection{Implications for theory}

It has emerged that the impact of dynamic capabilities and big data governance on the quality of decision making is contingent on variables such as firm size (number of employees) and firm age. From a theoretical perspective, this study has consolidated the basic idea in the literature (such as Henke et al., 2016; Manyika et al., 2011) that big data contribute to effective decision-making. That is, big data governance's value is not only for amassing information; via predicting analytics, but they can as well be employed towards decision making that transforms the way organizations operate. While this study does show valuable empirical results, in addition to that, it still contributes to existing knowledge on big data analytics precisely by considering big data governance as an asset that can work side-by-side with dynamic capabilities for an organization's effective decision making. In addition, the current study is one of the handfuls to operationalize and empirically test the sensing, seizing and transforming the view of dynamic capabilities as noted in (Torres et al., 2018) work. Thus, the article contributes to this research stream. This study also makes the big data literature more robust by the filling a gap that has been identified by scholars (such as, Mikalef et al., 2015; Torres et al., 2018) in expanding the frontiers of the relationship tested to include contingent and organizational factors such as firm age, type of industry and firms size. Theoretically, this study validates fsQCA arguments that multiple configurations are appropriate in explaining complex phenomenon. 


\subsection{Implications for practice}

Essentially, this study has unveiled the idea that data-driven decisions are more effective. For managers, the use of big data and its governance ensures informed evidenced-based decision-making. The findings support the debate that big data governance may be regarded as a strategic asset that significantly and positively influences the organization all-round. In demonstrating the causal relationship between big data governance and effective decision making, this research offers empirical proof that could be useful for senior managers seeking to defend their investments in big data governance. Therefore, firms should hire data analytic experts to unpack the patterns in data and transform them into valuable business information. This article recommends that firms should develop and implement corporatewide big data mechanisms, standards, guidelines and policies that can promote big-data analytics that are consistent with the organization's culture, norms, values, strategy and mission (Weill, 2004). Furthermore, the implications of this study's findings for management are that firms with operations in environments that are dynamic can effectively adjust their current business model by employing big data analytics and different combinations of dynamic capabilities.

The survey data is cross-sectional and subjective in nature which limits the casual interference. Although, anonymity and confidentiality were assured the threat of social desirability bias cannot be eliminated completely. Future studies are advised to utilize longitudinal or panel data to improve the reliability and validity of the outcome. The use of other methodological approaches e.g., artificial neural network is encouraged (Abubakar et al., 2019). Consequently, other concept such as robustness capability, absorptive capacity, resilience capability etc. can be incorporated to provide deeper insights.

\section{References}

Abubakar, A. M., Elrehail, H., Alatailat, M. A., \& Elçi, A. (2017). Knowledge management, decisionmaking style and organizational performance. Journal of Innovation \& Knowledge, 4(2), 104-114.

Abubakar, A. M., Karadal, H., Bayighomog, S. W., \& Merdan, E. (2018). Workplace injuries, safety climate and behaviors: application of an artificial neural network. International Journal of Occupational Safety and Ergonomics, 1-11 https://doi.org/10.1080/10803548.2018.1454635

Abubakar, A. M., Behravesh, E., Rezapouraghdam, H., \& Yildiz, S. B. (2019). Applying artificial intelligence technique to predict knowledge hiding behavior. International Journal of Information Management, 49, 45-57.

Arend, R. J. (2014). Entrepreneurship and dynamic capabilities: how firm age and size affect the "capability enhancement-SME performance" relationship. Small Business Economics, 42(1), 3357.

Brynjolfsson, E., Hitt, L. M., \& Kim, H. H. (2011). Strength in numbers: How does data-driven decisionmaking affect firm performance? Social Science Research Network (SSRN). Retrieved from https://pdfs.semanticscholar.org/dde1/9e960973068e541f634b1a7054cf30573035.pdf

Carayannopoulos, S. (2009). How Technology-Based New Firms Leverage Newness and Smallness to Commercialize Disruptive Technologies. Entrepreneurship Theory and Practice, 33(2), 419-438.

Chan, Y. E., Sabherwal, R., \& Thatcher, J. B. (2006). Antecedents and outcomes of strategic IS alignment: an empirical investigation. IEEE Transactions on Engineering Management, 53(1), 2747.

Chen, M., Mao, S., Liu, Y., Chen, M., Mao, S., \& Liu, Y. (2014). Big Data: A Survey. Mobile Network Application, 19, 171-209.

Cole, Z. (2017). The Top 6 Benefits of Data Governance. Retrieved February 8, 2019, from https://erwin.com/blog/top-6-benefits-of-data-governance/.

Davenport, T., \& Harris, J. (2017). Competing on Analytics: Updated, with a New Introduction: The New Science of Winning. Harvard Business Press. R

De Haes, S., \& Van Grembergen, W. (2015). Enterprise Governance of IT, Alignment and Value. In Enterprise governance of information technology. Achieving Alignment and Value, Featuring 
COBIT, 5. springer .

Fainshmidt, S., Pezeshkan, A., Lance, F. M., Nair, A., \& Markowski, E. (2016). Dynamic capabilities and organizational performance: A meta-analytic evaluation and extension. Journal of Management Studies, 53(8), 1348-1380.

Gandomi, A., \& Haider, M. (2015). Beyond the hype: Big data concepts, methods, and analytics. International Journal of Information Management, 35(2), 137-144.

Günther, W. A., Rezazade, M. ., Huysman, M., \& Feldberg, F. (2017). Debating big data: A literature review on realizing value from big data. The Journal of Strategic Information Systems, 26(3), 191209.

Helfat, C. E., Finkelstein, S., Mitchell, W., Peteraf, M., Singh, H., Teece, D., \& Winter, S. G. (2009). Dynamic capabilities: Understanding strategic change in organizations. John Wiley \& Sons.

Henke, N., Bughin, J., Chui, M., Manyika, J., Saleh, T., Wiseman, B., \& Sethupathy, G. (2016). The Age of Analytics: Competing in a data-driven world. Retrieved from www.mckinsey.com/mgi.

Hervas-Oliver, J.L., Sempere-Ripoll, F., \& Arribas, I. (2015). Asymmetric modeling of organizational innovation. Journal of Business Research, 68(12), 2654-2662

Jahmani, K., Fadiya, S. O., Abubakar, A. M., \& Elrehail, H. (2018). Knowledge content quality, perceived usefulness, KMS use for sharing and retrieval: A flock leadership application. VINE Journal of Information and Knowledge Management Systems, 48(4), 470-490.

Janssen, M., van der Voort, H., \& Wahyudi, A. (2017). Factors influencing big data decision-making quality. Journal of Business Research, 70, 338-345.

Jantunen, A., Tarkiainen, A., Chari, S., \& Oghazi, P. (2018). Dynamic capabilities, operational changes, and performance outcomes in the media industry. Journal of Business Research, 89, 251257.

Karna, A., Richter, A., \& Riesenkampff, E. (2016). Revisiting the role of the environment in the capabilities-financial performance relationship: A meta-analysis. Strategic Management Journal, 37(6), 1154-1173.

Kung, L., Kung, H.-J., Jones-Farmer, A., \& Wang, Y. (2015). Managing Big Data for Firm Performance: a Configurational Approach. In Twenty-first Americas Conference on Information Systems. Puerto Rico.

Lee, I. (2017). Big data: Dimensions, evolution, impacts, and challenges. Business Horizons, 60(3), 293-303.

Manyika, J., Chui, M., Brown, B., Bughin, J., Dobbs, R., Roxburgh, C., \& Hung Byers, A. (2011). Big data: The next frontier for innovation, competition, and productivity. Retrieved from https://www.mckinsey.com/ /media/mckinsey/business functions/mckinsey digital/our insights/big data the next frontier for innovation/mgi_big_data_exec_summary.ashx

McAfee, A., \& Brynjolfsson, E. (2012, October). Big Data: The Management Revolution. Harvard Business Review. Retrieved from http://tarjomefa.com/wp-content/uploads/2017/04/6539-EnglishTarjomeFa-1.pdf

Mithas, S., Ramasubbu, N., \& Sambamurthy, V. (2011). How information management capability influences firm performance. MIS quarterly, 35(1), 237.

Mikalef, P., \& Krogstie, J. (2018). Big Data Governance and Dynamic Capabilities: The Moderating effect of Environmental Uncertainty. In Twenty-Second Pacific Asia Conference on Information Systems. Japan.

Mikalef, P., Pateli, A., Batenburg, R. S., \& Van De Wetering, R. (2015). Purchasing alignment under multiple contingencies: A configuration theory approach. Industrial Management and Data Systems, 115(4), 625-645.

Olya, H. G., \& Gavilyan, Y. (2017). Configurational models to predict residents' support for tourism development. Journal of Travel Research, 56(7), 893-912.

Pezeshkan, A., Fainshmidt, S., Nair, A., Lance, F. M., \& Markowski, E. (2016). An empirical assessment of the dynamic capabilities-performance relationship. Journal of Business Research, 69(8), 2950-2956. 
Podsakoff, P., MacKenzie, S., Lee, J., \& Podsakoff, N. (2012). Sources of method bias in social science research and recommendations on how to control it. Annual Review of Psychology, 63, 539-69

Ragin, C.C. (1987). The Comparative Method: Moving beyond Qualitative and Quantitative Strategies. University of California Press, Berkeley and Los Angeles, CA.

Ragin, C. (2008). Redesigning Social Inquiry. University of Chicago Press, Chicago, CA.

Ragin, C. C., \& Fiss, P. C. (2008). Net effects analysis versus configurational analysis: An empirical demonstration. In Redesigning social inquiry: Fuzzy sets and beyond (pp. 190-212).

Shamim, S., Zeng, J., Shariq, S. ., \& Khan, Z. (2018). Role of big data management in enhancing big data decision-making capability and quality among Chinese firms: A dynamic capabilities view. Information \& Management. https://doi.org/10.1016/J.IM.2018.12.003.

Teece, D. J. (2007). Explicating dynamic capabilities: The nature and microfoundations of (sustainable) enterprise performance. Strategic Management Journal, 28(13), 1319-1350.

Torres, R., Sidorova, A., \& Jones, M. C. (2018). Enabling firm performance through business intelligence and analytics: A dynamic capabilities perspective. Information \& Management, 55(7), 822-839.

Wamba, S. F., Gunasekaran, A., Akter, S., Ren, S. J. F., Dubey, R., \& Childe, S. J. (2017). Big data analytics and firm performance: Effects of dynamic capabilities. Journal of Business Research, 70, 356-365.

Wang, Y., \& Byrd, T. A. (2017). Business analytics-enabled decision-making effectiveness through knowledge absorptive capacity in health care. Journal of Knowledge Management, 21(3), 517-539.

Weber, K., Otto, B., \& Österle, H. (2009). One Size Does Not Fit All---A Contingency Approach to Data Governance. Journal of Data and Information Quality, 1(1), 1-27.

Weill, P. (2004). Don't just lead, govern: How top-performing firms govern IT. (No. CISR WP No. 341 and Sloan WP No. 4493-04) (Vol. 8). Cambridge, MA. Retrieved from http://mitsloan.mit.edu/cisr

Wilhelm, H., Schlömer, M., \& Maurer, I. (2015). How Dynamic Capabilities Affect the Effectiveness and Efficiency of Operating Routines under High and Low Levels of Environmental Dynamism. British Journal of Management, 26(2), 327-345.

Woodside, A.G. (2013). Moving beyond multiple regression analysis to algorithms: calling for adoption of a paradigm shift from symmetric to asymmetric thinking in data analysis and crafting theory. Journal of Business Research, 66(4), 463-472.

Zollo, M., \& Winter, S. G. (2002). Deliberate Learning and the Evolution of Dynamic Capabilities. Organization Science, 13(3), 339-351.

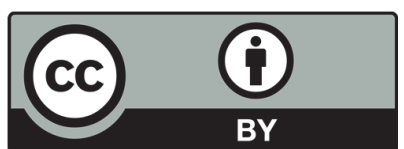

(C) 2019 by the authors; licensee Growing Science, Canada. This is an open access article distributed under the terms and conditions of the Creative Commons Attribution (CC-BY) license (http://creativecommons.org/licenses/by/4.0/). 